\title{
INCIDENCE OF NEONATAL HYPERBILIRUBINEMEA IN TERM NEW BORNS AT KBNTGH
}

\author{
Mujumdar V. G1, Siddaling Changty22, Preethi Amarkhed³, Nabeel Nazeer4, Harshavardhan ${ }^{5}$ \\ ${ }_{1}^{1}$ Associate Professor, Department of Paediatrics, Khaja Banda Nawaz Institute of Medical Sciences, Kalaburgi. \\ 2 Professor and HOD, Department of Paediatrics, Khaja Banda Nawaz Institute of Medical Sciences, Kalaburgi. \\ ${ }^{3}$ Assistant Professor, Department of Paediatrics, Khaja Banda Nawaz Institute of Medical Sciences, Kalaburgi. \\ 4Junior Resident, Department of Paediatrics, Khaja Banda Nawaz Institute of Medical Sciences, Kalaburgi. \\ 5 Junior Resident, Department of Paediatrics, Khaja Banda Nawaz Institute of Medical Sciences, Kalaburgi.
}

ABSTRACT: AIM AND SCOPE: We conducted this study to estimate the incidence of hyperbilirubinemia in term new born with birth weight $>2.5 \mathrm{kgs}$ born at neonatal care unit of KBNTGH, and to determine the underlying causes, which would be of value in identifying and implementing strategies to prevent morbidity from this condition.

BACKGROUND: Management of hyperbilirubinemia remains a challenge for neonatal medicine because of the risk for serious neurological complications related to the toxicity of bilirubin.

MATERIALS AND METHODS: From January 2014 to January 2015, we screened 525 newborns born at KBNTGH (Khaja Bandanawaz Teaching \& General Hospital attached to Khaja Bandanawaz Institute of Medical Sciences)with complaints of yellowish discoloration of skin were screened for jaundice. Infants aged 3-5 days and with unconjugated hyperbilirubinemia were included for assessment if they had a peak serum total bilirubin level exceeding $10 \mathrm{mg} / \mathrm{dl}$. Sex, birth weight, gestational age, breast feeding, type of birth, presence of facial bruising (Including cephalohematoma) and ABO group were noted. Patients with Toxoplasma or Cytomegalovirus infection, hepatic insufficiency, or suspected drug-induced hyperbilirubinemia were excluded from more detailed analysis.

RESULTS: Our year-long nursery sample examined otherwise healthy-appearing term infants with birth weigth $>2.5 \mathrm{kgs}$ for the prevalence of hyperbilirubinemia (Defined as bilirubin levels exceeding $6 \mathrm{mg} / \mathrm{dL}$ [11 mol/L]). We found hyperbilirubinemia in $19 \%$ (100/525). Among the patients with hyperbilirubinemia, $1.2 \%$ had peak levels of bilirubin $20 \mathrm{mg} / \mathrm{dL}$, levels which are generally considered to be potentially neurotoxic.

CONCLUSIONS: In our clinic experience, hyperbilirubinemia was generally a serious medical issue and one whose etiology can usually be well defined.

KEYWORDS: Hyperbilirubinemia, Phototherapy, Kernicterus.

HOW TO CITE THIS ARTICLE: Mujumdar.V.G, Siddaling Changty, Preethi Amarkhed, Nabeel Nazeer, Harshavardhan. "Incidence of Neonatal Hyperbilirubinemea in Term New Borns at KBNTGH". Journal of Evolution of Medical and Dental Sciences 2015; Vol. 4, Issue 91, November 12; Page: 15679-15681, DOI: 10.14260/jemds/2015/2256.

INTRODUCTION: Severe hyperbilirubinemia continues to be the most common cause of neonatal readmission for hospitals in India .This pattern continues despite attempts to identify newborns at risk of clinically important hyperbilirubinemia before they are discharged from hospital. Long-term results of severe hyperbilirubinemia, including bilirubin encephalopathy and kernicterus, were thought to be rare since the advent of exchange transfusion, maternal $\mathrm{Rh}$ immunoglobulin prophylaxis, and phototherapy. However, cases of kernicterus have been reported recently in healthy near-term and term infants without evidence of hemolytic disease or other risk factors. We begin our study of this problem with a survey of a single clinic experience over a year with respective to severity and probable causes of hyperbilirubinemia.

BACKGROUND: Management of hyperbilirubinemia remains a challenge for neonatal medicine because of the risk for serious neurological complications related to the toxicity of bilirubin.

Financial or Other, Competing Interest: None.

Submission 05-10-2015, Peer Review 06-10-2015,

Acceptance 29-10-2015, Published 11-11-2015.

Corresponding Author:

Dr. Mujumdar V. G,

\#34 INGO's Housing Colony,

Jewargi Road, Gulbarga.

E-mail: drmujumdarvg@gmail.com

DOI:10.14260/jemds/2015/2256.
The neonatal hyperbilirubinemiapractice guidelines published in 2004 by the Indian Academyof Pediatrics (IAP) expresses the pediatric community's concern regarding bilirubin-induced neurological pathology. Risk factors with severe hyperbilirubinemia in newborns have included jaundice in the first 24 hours of life, jaundice noted before discharge from hospital, a sibling who had jaundice treated with phototherapy, near-term gestational age of 35-36 weeks, and the presence of infant with bruising or cephalohematoma.

MATERIALS AND METHODS: From January 2014 to January 2015, we screened 525 newborns born at the Neonatal Care Unit of KBNTGH. Infants aged 3-5 days and with unconjugated hyperbilirubinemia were included for assessment if they had a peak serum total bilirubin level exceeding $10 \mathrm{mg} / \mathrm{dl} \quad(102 \mu \mathrm{mol} / \mathrm{L})$. Sex, birth weight, gestational age, breast feeding, type of birth, presence of facial bruising (Including cephalohematoma), and ABO group were noted. Patients with Toxoplasma or Cytomegalovirus infection, hepatic insufficiency, or suspected drug-induced hyperbilirubinemia were excluded from more detailed analysis. We focused on healthy term infants without risk factors. Infants who had known Rh iso-immunization were excluded since antenatal and postnatal strategies already exist to prevent the occurrence of severe neonatal hyperbilirubinemia from this cause. 
Infants who were born at less than 36 weeks gestational age were also excluded as well as newborn with severe facial bruising or cephalohematoma from more detailed analysis. Data were summarized using descriptive statistics. Continuous variables were analyzed using the independent Student's t-test and Fisher's exact test. A chi -square test was used to test associations between all other categorical variables.

RESULTS: We found 100children with unconjugated hyperbilirubinemia. Causes identified by laboratory investigations include $\mathrm{Rh}$ and $\mathrm{ABO}$ incompatibility, as well as glucose-6-phosphate dehydrogenase (G6PD) deficiency. We found potentially neurotoxic levels of hyperbilirubinema in only one case, with value of peak bilirubin of $20 \mathrm{mg} / \mathrm{dL}$ ( $342 \mathrm{mmol} / \mathrm{L})$, treated with phototherapy. The other 99cases had milder hyperbilirubinemia and did not receive any treatment. In our series, we found breastfeeding in 65 cases, cesarean section in 61, and mild facial bruising in 16 . Medications during the pregnancy were used in 39cases and post-pregnancy in 35 (Table 1).

A single case showed evidence of liver disease (Gilbert disease). Cytomegalovirus and toxoplasmosis infection were found in $2 \%$ and $6 \%$ of the cases, respectively (Table 1 ). Maternalmicrocytosis was found in two cases. We also evaluated the $\mathrm{ABO}$ group in the mothers and in the newborns (Table 2). No significant differences were found in the examined group. No other risk factors were found in those patients. We tried to analyze the characteristics of neonatal jaundice. We took in consideration over 525 children, 100 infants with a value of bilirubin level of more than $10 \mathrm{mg} / \mathrm{dl}$ (102 $\mu \mathrm{mol} / \mathrm{L})$ (Table 3).

DISCUSSION: Hyperbilirubinemia is felt to be a benign condition for infants born at term or near-term gestation. In around $5 \%$ of healthy term infants, however, serum bilirubin values exceed $17 \mathrm{mg} / \mathrm{dL}$ (291 mmol/L), a value which the AAP deems significant. Levels exceeding $20 \mathrm{mg} / \mathrm{dL}(342$ mmol/L) occur in $1.2 \%$ of healthy newborn infants. Thevastmajorityof infants with serum bilirubin values of 20 $\mathrm{mg} / \mathrm{dL}$ remain well; mostly need minimal care other than the occasional use of phototherapy and careful monitoring of serum levels.

Before 1990, kernicterus in the previously healthyterm infant was extraordinarily rare and for most pediatricians, it was a disease they were unlikely to see in their practice lifetimes. Since 1990, there has been an increase in the number of reported cases of kernicterus in India. Thirty-one cases have been reported in term infants who were well at the time of hospital discharge, and several additional cases have occurred in near-term infants.

Although it is unknown whether there is an actual increase in the incidence of kernicterus in the India or simply better detection, reported cases are thought to be attributable to a variety of events including: shortened hospital stays with inconsistent follow-up beyond discharge; an increase in the frequency of breastfeeding; and a lack of concern about high bilirubin levels among pediatric care providers.

Although the relationship between hyperbilirubinemia and brain injury in healthy term infants has been recently questioned, in a re-evaluation of the data from the Collaborative Perinatal Project, Newman and Klebanoff could not demonstrate a relationship between bilirubin levels $26 \mathrm{mg} / \mathrm{dL}(342 \mathrm{uM} / \mathrm{L})$ and an abnormal neurologic examination.[4]

Breastfeeding is still debated as probably an important variable in these patients. In the present series, almost $65 \%$ of hyperbilirubemic patients were breastfed, as it has been for the other cases of kernicterus reported in the literature. In our series, no significance statistical difference in bilirubin levels were found according to whether or not the infant was breastfed. In a case-controlled study, Maiselsfound that hyperbilirubinemia was the major reason for hospital readmission during the first two weeks of life.[3]

Moreover, the majority of the jaundiced infants in their study were breastfedandhada greater mean weight loss since birth than non -jaundiced controls, suggesting that even mild degrees of dehydration in conjunction with breastfeeding impacts on the severity of hyperbilirubinemia. Our series comes from a small center in KBNTGH, kalaburgi.

Kalaburgi is one of the sunniest spots on Earth. It is possible that this plays some role in the relatively low incidence of hyperbilirubinemia in our studies as compared to previous studies. Furthermore future studies should investigate the presence of individual susceptibility, environmental factors, especially environmental climate (Daylight), and genetic factors to explain the different incidences of the disease, and the frequency of such findings in infants with moderate degrees of hyperbilirubinemia and possible modes of prevention and new therapeutic strategies.

\section{REFERENCES:}

1. Maisels MJ, Newman TB. Jaundice in full-term and nearterm babies who leave the hospital within 36hrs.Clin Pernatol.1998; 25:295-302.

2. Worley G, Erwin CW, Goldstein RF, et.al .Delayed development of sensorineural hearing loss after neonatal hyperbilirubinemia: a case report with brain magnetic resonance imaging. Dev med child neurol.1996; 38:271-278.

3. Maisels MJ, Gifford. K, Antle CE. Normal serum bilirubin levels in the new born and the effect of breast feeding. Pediatrics.1986; 837-843.

4. Maisels MJ, Newman TB. Kernicterus in otherwise healthy, breast fed term newborns.

Pediatrics.1995; 96:730-733.

5. MaiselsMJ, Kring. E. Length of stay, Jaundice and hospital readmission.Pediatrics.1998; 101:995-998.

6. NewmanTB, Maisel MJ. Evaluation and treatment of Jaundice and in the term newborn: a kinder and gentler approach.Pediatrics.1992; 89:809-818. 


\begin{tabular}{|c|c|c|c|c|}
\hline Sl. No. & Factors & Yes & No & Total \\
\hline 1 & Breastfeeding & 65 & 35 & 100 \\
\hline 2. & Cesarian Section & 61 & 39 & 100 \\
\hline 3. & Spontaneous Delivery & 39 & 61 & 100 \\
\hline 4. & Bruising Face & 16 & 84 & 100 \\
\hline 5. & Drugs in Pregnancy & 39 & 61 & 100 \\
\hline 6. & Drugs after Pregnancy & 35 & 65 & 100 \\
\hline 7. & Liver Disease & 1 & 99 & 100 \\
\hline 8. & Cytomegalovirus & 2 & 98 & 100 \\
\hline 9. & Microcytemic Mother & 2 & 98 & 100 \\
\hline 10. & Toxoplasmosis in Pregnancy & 6 & 94 & 100 \\
\hline \multicolumn{5}{|c|}{ Table 1: Pregnancy Factors } \\
\hline
\end{tabular}

\begin{tabular}{|c|c|c|c|}
\hline Sl. No. & Blood Group & Maternal Group & Baby Group \\
\hline 1 & O Negative & 5 & 6 \\
\hline 2. & O Positive & 52 & 48 \\
\hline 3. & A Negative & 2 & 2 \\
\hline 4. & A Positive & 17 & 29 \\
\hline 5. & B Negative & 6 & 1 \\
\hline 6. & B Positive & 16 & 13 \\
\hline 7. & AB Negative & 2 & 1 \\
\hline 8. & AB Positive & 0 & 0 \\
\hline \multicolumn{4}{|c|}{ Table 2: Blood Groups } \\
\hline \multicolumn{4}{|c|}{} \\
\hline
\end{tabular}

\begin{tabular}{|c|c|}
\hline Sl. No. & Blood Group \\
\hline 1 & N (\%) of infants * \\
\hline 2. & n=100 \\
\hline 3. & Gestational age: wk Mean (SD) $38.5(1.4)$ \\
\hline 4. & Birth weight, g, mean (SD) 3250 (+/- 489) \\
\hline 5. & Age at Presentation of Jaundice, h, mean (SD) 78.5 \\
\hline 6. & Breast-feeding 65 \\
\hline 7. & Peak total bilirubin level, $\propto$ mol/L. \\
\hline 8. & mean (SD), $186( \pm 76)$ \\
\hline 9. & Table 3: Characteristics \\
\hline
\end{tabular}

\begin{tabular}{|r|c|c|c|}
\hline $\begin{array}{c}\text { Day of Development } \\
\text { of term Babies }\end{array}$ & Day-3 & Day-4 & Day-5 \\
\hline Total No. & 32 & 50 & 23 \\
\hline Percentage & $30.13 \%$ & $45.32 \%$ & $23.35 \%$ \\
\hline Table 4: Distribution for 100 Newborn's \\
Jaundice Relating to Day of Development \\
\hline
\end{tabular}

